Modern Asian Studies 54, 3 (2020) pp. 868-897. (C) The Author 2019. This is an Open Access article, distributed under the terms of the Creative Commons Attribution licence (http:// creativecommons.org/licenses/by/4.o/), which permits unrestricted re-use, distribution, and reproduction in any medium, provided the original work is properly cited. doi:I0.1017/Soo26749Xi80oo47I First published online io September 2019

\title{
The Teacher, the Activist, and the Maulvi: Emancipatory visions and insurgent citizenship among Gujjars in Himachal Pradesh*
}

\author{
RICHARD AXELBY \\ Department of Anthropology and Sociology, SOAS University of London \\ Email: ra39@soas.ac.uk
}

\begin{abstract}
Exploring the intersection of state, religion, and ethnicity, this article considers the opportunities for individual and collective advancement available to Muslim Gujjars in Chamba district of Himachal Pradesh. Following the lives of three prominent members of the community - a teacher, a political activist, and a maulvi - it considers their respective orientations to the state and their relationships with their fellow Gujjars, to illustrate the different ways in which Gujjars have sought to transcend their marginal and subordinated position as an ethnic and religious minority. With state-promoted schemes of affirmative action and reservation offering only limited opportunities for social and economic advancement, we see how Gujjars have responded to their continued marginalization, first through political mobilization as an ethnic group and, more

* The research that contributed to this article was conducted between 2014 and 2016 as part of the Research Programme on Inequality and Poverty based in the Department of Anthropology, London School of Economics (funded by the ESRG and the EU, Principal Investigator: Alpa Shah). Additional fieldwork took place as part of the AHRC GCRF-funded project, 'Deepening democracy in extremely politically fragile countries' (AH/Roo5435/I; Principal Investigator: Emma Crewe; Department of Anthropology and Sociology, SOAS University of London). I am indebted to Emma Crewe, Shruti Herbert, Stephen Cristopher Johnson, Jonathan Parry, Jayaseelan Raj, Shreya Sinha, Alpa Shah, Vikramaditya Thakur, and two anonymous reviewers for their thorough engagement with this article and their extremely helpful feedback. An early version of this article was presented as part of the Inequality and Poverty Seminar Series held at LSE in 2016 and I am grateful to the participants for the initial comments and ongoing support they provided. None bears any responsibility for what I have written here.
\end{abstract}


recently, through the establishment of Islamic educational institutions and association with Tablighi Jama'at. This leads to an evaluation of the emancipatory potentials and contradictions of insurgent citizenship when mobilized around specific aspects of ethnic and religious identity. Against a backdrop of economic liberalization and accompanying shifts in civil society, I show how the distribution of rewards that derive from strategies of assimilation, engagement, and withdrawal are structured in particular ways, including by class and gender.

\section{Muslim ST Gujjars in Chamba district}

Across a wide swathe of the Western Himalayas, nomadic buffalo-herding Gujjars have historically moved their animals from low-lying winter pastures up to alpine meadows where they spend the summer months. Tracing their origins to Kashmir, Gujjar families began to arrive in the Chamba valley towards the end of the nineteenth century. These Gujjars were incorporated into the then princely state of Chamba as subjects of the Chamba kings and claimed rights to graze animals and farm land directly from the Raja. Then, following independence in I947, the kingdom was absorbed into the newly created state of Himachal Pradesh and the subjects of the Chamba Raja became citizens of a free India. On account of their unique culture, language, and dress, and the 'backwardness' of their traditional nomadic occupation, in I950, Gujjars residing in the newly created Chamba district were granted Scheduled Tribe (ST) status. Here, it is worth noting that, unusually for an ST community, the Gujjars in Chamba district are uniformly Muslim. This article considers what citizenship means for Muslim ST Gujjars in Chamba district and the ways in which administrative definitions have interacted with social and economic aspirations to produce emancipatory visions for insurgent citizenship. It does so by considering first the limited benefits that some Gujjars gained from affirmative action schemes, goes on to suggest that political mobilization among the Gujjars depends on the acceptance of a subordinate 'tribal' social status, and finally explains why Gujjars are increasingly seeking to benefit from association with networks of Islamic religious teaching. In this way, the article delineates the potentials and limits for advancement and traces how individual and collective capacities to aspire have been mediated with and through the state.

Tucked away in the far west of the Himachal Pradesh, Chamba district's developmental performance is among the least impressive in the state. Chamba district has comparatively low levels of literacy and 
life expectancy, and the lowest income per capita in Himachal Pradesh. ${ }^{1}$ Chamba also has the largest ST population of any of the 12 districts in Himachal Pradesh. ${ }^{2}$ ST families in Chamba are over-represented among those living below the poverty line (BPL) and amongst the poorest of the poor. Two subdivisions of Chamba district (Bharmour and Pangi) have been brought together as a Scheduled Area, which allows them the benefits of a greatly enhanced budget. Because few Gujjars have their permanent homes in the subdivisions, the assistance from this tribal sub-plan has gone mainly to Gaddis - another agro-pastoralist ST group - that are the majority population of Bharmour.

The geographical focus of this article takes us away from the tribal sub-district to a group of villages lying in the Saal valley about I5 kilometres north of the district capital of Chamba town. Of the 122 households (6I2 individuals) in Badagaon Panchayat, ${ }^{3}$ around two-thirds are caste Hindu (Rajput, Goswami) or Scheduled Caste (SC). The 200 individuals of the remaining households ${ }^{4}$ are classified as ST-some Gaddi but mostly Gujjar. In terms of education and jobs, the general population of caste Hindus and Muslims possess the longest history of schooling and monopolize employment opportunities in the state and private sector. ${ }^{5}$ In contrast, most of the Gujjar households in Badagaon depend upon combinations of small-scale agriculture, unskilled manual labour, and the keeping of buffalo, whose milk can be sold. Nearly seven decades after being granted ST status, the majority of the Gujjar population remain trapped at the bottom of the socio-economic hierarchy, with only a few having benefitted from state assistance in education and reservation of government posts.

${ }^{1}$ 54.I per cent of households in Chamba district are below the poverty line (BPL) against a Himachal Pradesh (H.P.) average of 23.9 per cent (source: Rural Development Department, H.P., Socio-Economic Indicators of Himachal Pradesh, Department of Economics and Statistics, Shimla, Himachal Pradesh, 2013).

${ }^{2}$ The 201 I census records an ST population of 135,500 in Chamba out of a district population of $5 \mathrm{I9}, 080$; the tribal population of H.P. is 392,126 out of a total state population of 6,864,602 (source: Socio-Economic Indicators of Himachal Pradesh, Department of Economics and Statistics, Shimla, Himachal Pradesh).

${ }^{3}$ Throughout this article, pseudonyms are used for people, organizations, and certain places.

${ }^{4}$ Source: Directory of Villages Having Concentration of Scheduled Tribe Population Excluding Scheduled Areas in Himachal Pradesh (20II-Census), issued by the Tribal Development Department, Government of Himachal Pradesh, Shimla.

${ }^{5}$ See Axelby in A. Shah, J. Lerche, R. Axelby, D. Benbabaali, B. Donegan, J. Raj, and V. Thakur, Ground Down by Growth: Tribe, Caste, Class and Inequality in Twenty-first-century India, Oxford University Press, Delhi, 2018. 
Exploring the intersection of state, religion, and ethnicity, this article considers the limited possibilities for individual and collective advancement available to Muslim Gujjars in the Chamba district of Himachal Pradesh. Doing so charts the means through which, against a backdrop of economic liberalization and accompanying shifts in civil society, Gujjars have sought to access government services, claim rights, achieve an education, find remunerative employment, and raise their social status. With state-promoted schemes of affirmative action and reservation offering only limited opportunities for social and economic advancement, we see how Gujjars have responded to their continued marginalization, first through political mobilization around a limited ethnic identity and, more recently, through the establishment of Islamic educational institutions and employment options that bypass the state. Moving beyond political rights and claims to resources, I go on to examine the ways in which Gujjars have sought to assert their social equality. Analysing these claims, this article seeks to articulate the varied and nuanced manner in which poor and disadvantaged Gujjars envisage emancipation. ${ }^{6}$

This article is structured around the lives of three prominent members of the Gujjar community in Badagaon - a teacher, an activist, and a maulvi - to consider their orientation to the state, their relationships with their fellow Gujjars, and the contrasting strategies through which

${ }^{6}$ Three recent collections - on affirmative action, political institutionalization, and emancipatory development - have shaped the analysis on which my empirical material is grounded. The articles brought together by A. Shah and S. Schneiderman (in Focaal - Fournal of Global and Historical Anthropology 65, 2013) demonstrate the value of anthropological approaches to understand the effects of affirmative action policies for differentiated citizenship in South Asia. J. Gorringe and Waghmore (eds.) (From the Margins to the Mainstream: Institutionalising Minorities in South Asia, Los Angeles, Sage, 2016) consider the results when formerly excluded groups are integrated into socio-political processes. The various chapters chart the ways by which people gain access to institutions and to unpack the consequences of these processes both for the groups in question and for the institutions that they enter. Finally, N. Jaoul and A. Shah's theme section in Focaal- Fournal of Global and Historical Anthropology (76, 2016) charts Adivasi and Dalit political pathways in India. In his introduction, Jaoul states the aim of the collection is to move beyond dominant, statist conception of citizenship when looking at the politicization of subaltern classes. Instead, ethnographers of 'insurgent citizenship' among Dalits and Adivasis are able to offer a view of emancipatory alternatives from below to illustrate the way political subjectivities are being produced on the ground by confronting, negotiating, but also exceeding the state and its policed frameworks (N. Jaoul, 'Beyond citizenship: Adivasi and Dalit political pathways in India', Focaal-Fournal of Global and Historical Anthropology 76, 2016, pp. 3-14). 
they have sought to transcend their social and political subordination as an ethnic and religious minority. Using the example of an educated and sophisticated high-school teacher, the first section looks at ST reservation policies and asks why affirmative action has proved limited in reach and impact. Government assistance enabled Allah Ditta to graduate from college and become a teacher. Though Allah Ditta considers himself a pace-setter for Gujjar development, he now feels estranged from the wider community. The second section shows how Gujjars have lost out as affirmative action schemes for education and jobs have become politicized. As the president of a Gujjar Community Rights Organisation (GCRO), social worker Hanif is committed to securing the rights and entitlements of Gujjar people. An increasingly influential actor in local politics, Hanif seeks to mobilize Gujjars as a disadvantaged and marginalized ethnic group. Here, we see how, in competition with other ST groups and non-ST groups, the Gujjars' lack of political connections and demographic numbers leaves them at a disadvantage. A third leading figure in the Gujjar community is Maulvi Zahid - a teacher in a newly created Islamic school. Downplaying 'tribal' aspects of Gujjar identity to highlight their religious beliefs, Zahid preaches the example of the Prophet Mohammed and encourages children to go to religious school. The popularity of Zahid's new madrasa demonstrates how many Gujjars are now actively rejecting secular education and reservation, and instead pursuing alternatives to government welfare schemes that they feel have done little to assist their development. This leads to an evaluation of the emancipatory potential of insurgent citizenships based upon forwarding particular aspects of ethnic and religious identity. Here, I show how the distribution of rewards and costs that derive from strategies of assimilation, engagement, and partial withdrawal are structured in particular ways, including by class and gender.

\section{Becoming 'modern' and leaving tribal identity behind}

Casually dressed in slacks and an untucked shirt, Allah Ditta is, in many ways, a thoroughly modern man. Allah Ditta serves me a glass of Coca-Cola in the reception room of his large modern house and tells me the story of how, through education, he was able to transcend his beginnings as a member of an ST in a remote rural area of Himachal Pradesh: 
Both of my parents were illiterate but my father was a hardworking and ambitious man. He farmed four acres of land and also ran a small business buying things from the town and selling them in the village. I have five brothers and my father tried to give an education to each of us. My two elder brothers began to be educated in school but did not continue - they could not understand the language of the teachers, or the way of teaching or the atmosphere of the school. They were not suited to it. I was third. When I joined the school [in 1965] I found it to be very good, the teachers were capable and affectionate. One teacher treated the students just like his own children. This was the reason I wanted to go to school. ${ }^{7}$

School suited Allah Ditta and, unlike his brothers, ${ }^{8}$ he continued to attend. After completing the village primary school, he went on to the high school a few kilometres away. The next step in Allah Ditta's education was to go to the boys' senior secondary school in Chamba town - a daily walk of I5 kilometres each way. Becoming the first person from the Gujjar community to matriculate led him on to Chamba College, where his high-caste Hindu batch-mates recall being surprised at seeing 'a man from a backward class' in their classroom. Upon graduation, Allah Ditta's father advised him to 'become a teacher and educate the people'. Allah Ditta travelled to Rajasthan to study for a B.Ed. and, on his return to Chamba, became a teacher in a government school. Over the years, he was promoted several times and eventually reached the status of principal in a senior secondary school. When I met him for the first time, he had recently retired - an event that was marked with a party and the granting of a pension.

Allah Ditta is a Gujjar and, as such, he is recognized by the state as belonging to the administrative category of ST. Recognizing that 'the weaker sections of the people' were deserving of special care and assistance, the post-independence Constitution of India created the official categories of SG and ST. These were to be the basis for a nationwide system of affirmative action. The criteria for establishing a set of people as an ST were only loosely defined but rested on a lack of social, educational, and economic development. Official measures to improve the position of ST communities were three-pronged: first, that they should be afforded protection though measures to shield against discrimination and punish practices that perpetuate inequities; the second set of measures were promotional - that is, ones that specified

\footnotetext{
${ }^{7}$ Allah Ditta, interview by author, Chamba, 27 April 2015.

${ }^{8}$ Very few female Gujjars of Allah Ditta's generation even made it as far as the doorways of a school.
} 
preferential treatment in allocation of jobs and access to higher education as well the reservation of seats in the Lok Sabha and in State Legislative Assemblies; third, the gap in social and economic development between $\mathrm{SC} / \mathrm{ST}$ s and other communities was to be bridged with developmental measures and resources. The intention was that communities that were economically, politically, and socially disadvantaged would be promoted into a notional national mainstream. The effect, as we shall see, is that group-differentiated citizenship works to create institutional incentives for the entrenchment of identities, and their reinforcement and hardening. ${ }^{9}$

In many ways, Allah Ditta embodies the ideal of 'social uplift' that was intended for disadvantaged tribal communities. He is educated and worldly, enjoyed his full career in government service, and, having reached the age of 58 , is now entitled to enjoy his retirement. Allah Ditta has spent his career with the clear idea that education should lead to the betterment of his community: 'first education then elevation.' This fits in with the view of formal education as a vehicle through which the position of previously disadvantaged social actors can be improved. Dreze and Sen promote this idea of education as a simple social good-increasing the skills base, knowledge, confidence, and freedoms of the poor, education is promoted as a route out of poverty and into good jobs. ${ }^{10}$ Allah Ditta was among a handful of young Gujjar men (notably there were no women among them) who benefitted from affirmative action in the r970s and I980s to obtain one of the good government jobs - as teachers, policemen, or administrators - that had previously been the exclusive domain of upper-caste Hindus and Muslims. These individuals, however, were the exception.

In Chamba, as elsewhere, the presence of individuals such as Allah Ditta within state institutions does not appear to have translated into overall social and economic upward mobility for Gujjars as a group. Why have so few Gujjars followed Allah Ditta in gaining educational qualifications and obtaining good government jobs? A number of anthropologists have employed Bourdieu's concept of social capital to show that, in India, the benefits that can be extracted from education are largely governed by people's pre-existing positions within systems of

\footnotetext{
${ }^{9}$ N. G. Jayal, Citizenship and Its Discontents: An Indian History, Harvard University Press, Cambridge, MA, 2013, p. 202.

${ }^{10}$ J. Dreze and A. Sen, Economic Development and Social Opportunity, Oxford University Press, Delhi, I995.
} 
social and economic inequality. Whether for low-caste Chamars in Uttar Pradesh. ${ }^{11}$ or Christian and Hindu Adivasis in Chhattisgarh, ${ }^{12}$ social connections are a prerequisite in order for educational capital to be successfully translated into economic capital in the forms of jobs. Jeffrey, Jeffery, and Jeffery describe how higher castes and classes are able to deploy 'money, social resources and cultural capital' to assist progress through the education system and into employment. ${ }^{13}$ Moving beyond institutional assistance, Higham and Shah have shown how, in Jharkhand, social advantage (or disadvantage) is translated into educational advantage (or disadvantage). ${ }^{14}$ Applying these lessons to Himachal Pradesh, we can see why, now and in the past, Chamba's Gujjars have struggled to complete with the dominant Rajput and Brahmin families, who have two or more generations of experience in securing good government jobs. Significant here are the ways by which a lack of cultural capital easily translates into forms of stigma. It is common for 'city-people' to dismiss 'jungli' rural Gujjars as backward, ignorant, and dirty: one college-educated informant laughingly told me that Gujjars understand the meaning of school year groups from class I to class 12 because the difference is linear, but they do not know the meaning of BA, MA, or B.Ed. because these are not. On the one side, most Gujjars lack the forms of capital required to make a success of education; on the other, they suffer from social stigma and discrimination for being uneducated.

And yet, as the example of Allah Ditta shows, some individuals from disadvantaged and excluded communities have been able to bridge this divide. Social mobility for Allah Ditta and others of his generation depended on not only gaining educational qualifications, but also on acquiring the kinds of cultural capital that permitted access to new contacts and networks of social relations. To become educated, to enter government service, and to achieve promotion within it required Allah

${ }^{11}$ M. Ciotti, 'In the past we were a bit "Chamar": education as a self- and community engineering process in northern India', Fournal of the Royal Anthropological Institute, I2(4), 2006, pp. $899-916$.

${ }^{12} \mathrm{P}$. Froerer, 'Education, inequality and social mobility in central India', European Fournal of Development Research, 23(5), 2011, pp. 695-71 I.

${ }^{13}$ C. Jeffrey, P. Jeffery, and R. Jeffery, Degrees without Freedom? Education, Masculinities and Unemployment in North India, Stanford University Press, Stanford, CA, 2008, p. 208.

${ }^{14}$ R. Higham and A. Shah, 'Conservative force or contradictory resource? Education and affirmative action in Jharkhand, India', Compare: A Journal of Comparative and International Education, 43(6), 2013, pp. 718-739. 
Ditta to accept and adopt forms of cultural capital recognized by the dominant group - the attitudes and attributes, style, taste, and wit of the cultivated classes. ${ }^{15}$ In appearance and clothing, Allah Ditta wears Western-style trousers and shirt rather than traditional Gujjar dress of kurta pyjama and waistcoat. His wife, though Muslim, is not a Gujjar and her links lie with the town. Assisted by the policies of reservation, Allah Ditta was able to advance as an individual by gaining acceptance within new social networks and, conforming to the policed framework of the state, becoming a model Indian citizen. The price of doing so is that he feels he had to leave his fellow Gujjars behind. Though wanting to assist the wider Gujjar community, Allah Ditta feels marginalized within it: 'they don't think of me as a person of their group. They think I am something different and don't listen to me. They see I don't have a beard or wear traditional clothes ... I want to do something for my community but they are against me. ${ }^{, 16}$

Affirmative action serves to raise beneficiaries up, but it also raises them out. ${ }^{17}$ With affirmative action conferring education and jobs on individual beneficiaries, such programmes can work to amplify social divisions and, in doing so, create new forms of inequality within the communities they are intended to assist. Though undoubtedly a success on a personal level, Allah Ditta agrees that others will struggle to replicate his achievements:

It was easier to get reserved posts when I was young. Now is the age of competition - if there is one post then hundreds of thousands of people will compete for it. And very few are actually selected on merit. Only those with political support will get the job. Political support is very necessary. ${ }^{18}$

${ }^{15}$ P. Bourdieu, 'The school as a conservative force? Scholastic and cultural inequalities', in J. Eggleston (ed.), Contemporary Research in the Sociology of Education, Methuen, London, I974, p. 39.

${ }^{16}$ Allah Ditta, interview by author, Chamba, 27 April 2015.

${ }^{17}$ Here, Parry's description of 'the aristocracy of Satnami labour' is apposite: 'distinction is manifest within the caste not only in terms of income, but also increasingly in terms of education, consumption patterns and styles of life.' J. Parry, 'Two cheers for reservation: the Satnamis and the steel plant', in R. Guha and J. Parry (eds.), Institutions and Inequalities: Essays in Honour of Andre Béteille, Oxford University Press, Delhi, I999, p. 155 .

${ }^{18}$ Allah Ditta, interview by author, Chamba, 27 April 2015. This view echoes Jeffrey and Lerche's account of recruitment to government service being widely viewed as based on corruption rather than merit: C. Jeffrey and J. Lerche, 'Stating the difference: state, discourse and class reproduction in Uttar Pradesh, India', Development and Change, 
Following independence, Adivasis and Dalits 'had to be reformed in order to become proper citizens'. ${ }^{19}$ Allah Ditta notes that, in his youth, his fellow Gujjars were not educated enough to vote. In many respects, Allah Ditta embodies a dominant, statist conception of citizenship in which the state is viewed as progressive, efficient, and capable of deploying its expertise to act upon and develop backward groups such as the Gujjars. Allah Ditta's current disillusionment suggests a departure from this Weberian ideal - a state that is contemporary but not 'modern', that is unnecessarily bureaucratic, inefficient, and, above all, political. In the next section, we see how a new generation of Gujjar social activists and politicians have understood the relationship between state and people in new and different ways. No longer can Adivasis and Dalits expect to be lifted up and transformed into 'proper citizens'; instead, Gujjar social activities have entered into dialogue with the state in order to claim from below their rights as citizens.

\section{Emphasizing the 'tribal' to seek advantage from ethnic identity}

Hanif Bhai is the president of the GCRO. Like Allah Ditta, Hanif Bhai comes from a family that, by virtue of owning good agricultural land, can be considered well-off by Gujjar standards. At his father's insistence, Hanif went to school and followed in Allah Ditta's footsteps by attending the boy's senior secondary school in Chamba town. He graduated in 1994. Context is important: two decades Allah Ditta's junior, Hanif Bhai grew up in an India politicized by the Mandal Commission Report, the destruction of the Babri Masjid, and the rise of regional parties and identity politics. Separated by a generation, the two men followed different routes into positions of leadership among Gujjars. This is reflected in their very different orientations to the idea of citizenship and the ways they expect state action might improve the lives of their community.

On leaving school, Hanif Bhai was hired by a local non-governmental organization (NGO) to work on a programme promoting education. This led to further employment on a similar project based in Chamba town

3I(4), 2000, pp. 857-878. See also S. Corbridge and J. Harriss, Reinventing India. Liberalization, Hindu Nationalism and Popular Democracy, Policy Press, Cambridge, 2000, p. 217.

${ }^{19}$ Jaoul, 'Beyond citizenship', p. 6. 
and funded by an international NGO. ${ }^{20}$ Through these schemes, Hanif became aware of and inspired by ideas of participatory and community-led development. At the same time, the reorientation of the Indian economy away from the state was opening up space for NGOs and civil-society activism. Hanif Bhai continues to work as an activist on several fronts, including organizing environmental protests against the creation of hydro-projects in Chamba. However, he is most closely associated with the GCRO. The GCRO was founded in 1997 with the aim of improving access to central and state government programmes for education, health, and employment. Hanif explains his role as being to act as a bridge between the people and the state. Grassroots campaigns and awareness-raising camps are held to disseminate knowledge of constitutionally guaranteed rights and enable people to claim them.

Hanif agrees with Allah Ditta that a lack of education is a crucial impediment to the Gujjars' development. He explained that, due to their families' migratory lifestyles, Gujjar children are educationally disadvantaged in comparison with other communities and the majority remain uneducated and illiterate. ${ }^{21}$ Through his work, Hanif campaigns for the unique position of nomadic Gujjars to be recognized. To this end, a number of Gujjar community hostels have been established with government support. These hostels allow students to continue their studies during the months when their parents take their buffalo up to the summer grazing pastures. The hope is that, with educational support, more Gujjars will be able to make the jump into good government jobs.

But, as we have seen, education alone is not enough. Contemporary development interventions that seek to classify populations for affirmative action purposes cannot be seen as proceeding simply in a top-down manner. Rather, such measures enter into pre-existing spaces of ethnic discourse and practice. Asked what would happen if a Gujjar went up for a job against an equally well-educated caste Hindu, ST Gaddi, or SC applicant, Hanif replied: 'If my son is as good as another candidate then it is difficult for my son to gain the job as we have no

${ }^{20}$ For more on NGOs, activists, and social movements in Chamba district, see K. Gaul, 'Shifting strategies in environmental activism in Chamba district of Himachal Pradesh', Himalaya, the Fournal of the Association for Nepal and Himalayan Studies, 2I(2), 200I, pp. 70-78.

${ }^{21}$ C. Dyer, 'Formal education and pastoralism in western India: inclusion, or adverse incorporation?', Compare: A fournal of Comparative and International Education, 42(2), 2012, pp. 259-28I. 
one in positions of power to help.' Hanif's comments make clear that the aim of affirmative action for Gujjars is now less about allowing individuals to advance on merit (that is, in competition with historically advantaged communities) and more about obtaining a share of the government posts allocated to them (that is, in competition with other segments of the SC/ST population). Being a minority ethnic group within the ST category, Gujjars are less adept at profiting from the political influence and social contacts that other ST and SC groups have been able to draw upon to reduce their education disadvantage and economic marginalization. ${ }^{22}$ In Himachal Pradesh, 7.5 per cent of government posts are put aside for ST applicants. (According to the 201 I Census of India, STs make up 5.7 per cent of the population of the state.) However, as Hanif pointed out, this puts ST Gujjars in competition for a limited number of government jobs with the much larger ST Gaddi and ST Pangiwal communities. Furthermore, both of these other two ST groups benefit from being represented by Thakur Singh Bharmouri, a Gaddi who is a member of the Legislative Assembly for the reserved constituency of Bharmour. Aiming to level what they perceive as an unequal playing field, Hanif's GCRO argues that, within the ST category, a separate percentage of government jobs should be reserved solely for Gujjars. Contrasting Allah Ditta with Hanif, we can see how, in one generation, affirmative action shifted from efforts to reverse 'backwardness' by bringing those classified as ST up to the level of the general population, to a competition between ST groups for the resources of the state. Reservation is here a zero-sum game.

With regard to efforts to reverse historical discrimination, Béteille distinguishes between those claims made for a fairer distribution of benefits on behalf of individuals (a 'meritarian principle' based on equality of opportunity) and those made on behalf of groups (a 'compensatory principle' based on equality of result). ${ }^{23}$ We have already seen with the case of Allah Ditta that efforts to allow individuals to advance on the basis of merit have met with, at best, only limited success. What, then, of efforts to claim a fairer distribution of benefits on behalf of groups? Though the intention of reservation was to reduce caste-consciousness by drawing historically excluded groups into a notional nation mainstream, Béteille warned that such policies were

${ }^{22}$ For more details, see the chapter by Axelby in Shah et al., Ground Down by Growth.

${ }^{23}$ A. Béteille, 'Distributive justice and institutional well-being', Economic and Political Weekly, 26(II/I2), March i99I, pp. 591-6oo. 
likely to reinforce rather than undermine caste and ethnic consciousness. ${ }^{24}$ Michelutti and Heath describe how, in recent decades, reservation policies attached to community entitlements have influenced the ways in which different caste and tribal groups see themselves and the ways in which they see others. This, in turn, shapes the ways different groups think about and participate in politics. ${ }^{25}$ The careers of several prominent Gujjars have been advanced through the $73^{\text {rd }}$ and $74^{\text {th }}$ constitutional amendments of 1992, which reserved seats in the bodies of local governance for SCs and STs. In panchayats such as Badagaon, where Gujjars make up a significant portion of the electorate, candidates from their community are well placed to win-particularly when the rotating reservation of seats designates that the candidate should be ST. Pointing to the example of Hanif, many voters stressed the importance when standing for election of having a reputation of holding 'good relations' with other communities, including high-caste Hindus, non-tribal Muslims, and ST Gaddis. Success in politics depends on accepting Gujjar identity, but not over-accentuating it; success also meant actively downplaying aspects of Muslim identity. Having been elected to the panchayat council, Hanif's wife, Sheena, can be included amongst those who hold a leadership position. When a seat on the panchayat is reserved for female candidates, it is not unusual for a man to advance his wife as a formal proxy while he holds the real power. This is not the case with Sheena, who campaigns alongside Hanif to promote reproductive rights and the education of girl children. Sheena explains that Gujjar women did not wear the veil-'it is not our tradition'26 and played an important role in promoting the interest of the community as a whole.

Utilizing the new political spaces opened up in India since the early I99os, Hanif Bhai, Sheena, and their fellow community leaders work to manage the 'collectivity-owned capital'" generated by Gujjars in

${ }^{24}$ A. Béteille, 'The backward classes and the new social order', in A. Béteille (ed.), The Idea of Natural Inequality and Other Essays, Oxford University Press, Delhi, I983, pp. 83-120.

${ }^{25}$ L. Michelutti and O. Heath, 'The politics of entitlement: affirmative action and strategic voting in Uttar Pradesh, India', Focaal-Journal of Historical and Global Anthropology, 65, Spring 2013, p. 57. See also S. Corbridge, G. Williams, M. Srivastava, and R. Véron, Seeing the State: Governance and Governmentality in Rural India, Cambridge University Press, Cambridge, 2005, p. I3.

${ }^{26}$ Sheena Begum, interview by author, Chamba, I4 January 2015.

${ }^{27}$ P. Bourdieu, 'The forms of capital', in J. Richardson (ed.), Handbook of Theory and Research for the Sociology of Education, Greenwood, New York, I986, pp. 241-258. 
Chamba as a resource to attract state services, resources, and benefits. While Allah Ditta's is an example of how citizens are actively made by states, the case of Hanif Bhai draws attention to processes by which social movements may enter into a dialectical relation with the state in order to challenge its foreclosures and claim the rights they believe are due to them. Shani ${ }^{28}$ writes of citizenship as both an axis in terms of engagement between individuals, social groups, and the state, and a mechanism for determining how prospective diverse groups should be delimited and what action should result from their solidarity. Based on ideals of political equality embedded in the Indian constitution, Hanif's political activism is a means of making claims for the bundle of rights and obligations that he understands form the basis of citizenship. Concretely, this is done by raising awareness about different social policies, advocating to ensure that social-protection schemes such as the Mahatma Gandhi National Rural Employment Guarantee Scheme (NREGA) are properly implemented, and campaigning for resources to be allocated to Chamba's Gujjar community.

Jaoul writes of how ideological encounters between people's movements and governmental politics work to contest state attempts to monopolize the political process, thus opening up possibilities 'for hybrid and creative political cultures of insurgent citizenship'. ${ }^{29}$ If the provision of social welfare suggests benefits being handed down from above to passive recipients, the reality is of political struggles that work from the bottom up. Empowerment from below requires 'the mobilisation and assertion of marginal actors which endows them with a sense of their own power to effect social change'. ${ }^{30}$ However, this is an aspiration that is easier to make than it is to achieve. Using the example of Hanif Bhai and the Gujjars, the remainder of this section considers the politics and limitations of insurgent citizenship's dialectical engagement with the state.

Seeking to represent the interests of Adivasi and Dalit communities by engaging with the state on their behalf, those individuals who occupy prominent positions in political organizations are generally those who have already enjoyed a degree of upward mobility. In Chamba district, Hanif's position has been strengthened over time through the

${ }^{28}$ O. Shani, 'Conceptions of citizenship in India and the "Muslim question", Modern Asian Studies, 44(I), 2010, p. I48.

${ }^{29}$ Jaoul, 'Beyond citizenship', p. 4. Jaoul borrows the concept of 'insurgent citizenship' from Holston's work on political mobilization in Brazil: J. Holston, 'Insurgent citizenship in an era of global urban peripheries', City and Society, 2I(2), 2009, pp. 245-267.

${ }^{30}$ Gorringe and Waghmore, From the Margins to the Mainstream, p. xxix. 
establishment of political links above the level of the panchayat. Promoting the party as pro-Gujjar at the panchayat level, pro-tribal at the district level, pro-poor at the state level, and pro-minorities (including Muslims) at the national level, Hanif Bhai successfully mobilizes the congress vote in Badagaon. This has allowed him to develop ties to prominent districtand state-level politicians. Gaining political recognition and acceptance is a central goal of marginalized groups. However, to view this as an end in itself rather than a step in a longer process would be to imbue processes of political representation with more significance than they possess. ${ }^{31}$ Gorringe et al. ${ }^{32}$ caution against accounts that celebrate the ascension of marginal actors to political institutions as a 'seismic shift' or a 'silent revolution'. In doing so, they warn that the more radical aims of Adivasi and Dalit movements can be diluted as their representatives enter into mainstream state and political arenas.

Hanif Bhai and others like him have succeeded in effectively transforming the social identity of Gujjar into an explicitly political identity. Central to the political enterprises established by this class of political leaders is the promotion of a notion of Gujjars in Chamba as a unified and bounded ethnic group distinct from other communities. Activists skilfully use indigeneity discourse to stress Gujjars' traditional nomadism, their historical exclusion, and their dependence on the natural resources of the forest. This is clearly effective when campaigning for recognition of Gujjars' access to grazing pastures under the Forest Rights Act or seeking compensation for those displaced by the construction of micro hydro-projects along the Saal River. Success in these campaigns was possible because Hanif was able to mobilize the Gujjars community in ways that did not actively antagonize the wider non-tribal population.

Spanning community service and politics, the work of this new generation of political leaders is laudable. However, it is worth asking whether the strategic price of gaining improved access to some state resources and services has been the institutionalization of community politics and acceptance of an essentialized 'backwards' identity for Gujjars. Recognized by Parry as 'the Koli Dilemma', there is a necessary trade-off between being able to access government benefits and the struggle for social prestige. ${ }^{33}$ Making claims on the state does

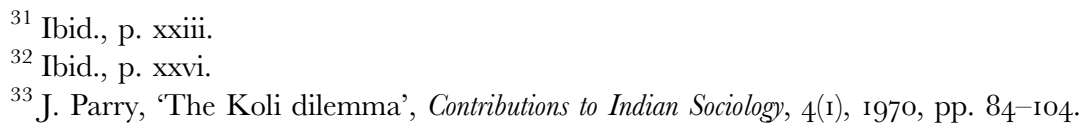


little to challenge social stigma and may work to reinforce negative stereotypes of the 'dirty, uneducated, backwards' Gujjar. ${ }^{34}$ As such, Gujjars risk being caught in a discursive trap that renders them as lesser citizens. ${ }^{35}$ On the one hand, politicizing Gujjars' ethnic identity assists with making claims for government assistance but, on the other, it makes it harder to compete with non-ST groups who benefit from their superior cultural capital. Being both a Muslim minority in a Hindu state and a socially stigmatized ethnic minority within the ST category, the Gujjar dilemma is more challenging than the one that Parry describes the Kolis of Kangra as having faced in the ig6os.

Claims to citizenship can be understood as simultaneously enabling and constraining radical projects and popular social movements. Through engagement with the institutional bureaucracies of the state, movements that aim to represent the marginalized may find themselves pressurized to alter their critiques, demands, and practices. ${ }^{36}$ As was the case with Allah Ditta, so too Gujjar politicians such as Hanif may be incorporated into hierarchies that promote their position as community leaders. However, the wider benefits stemming from their integration remain partial and limited. As such, movements promoting political equality often reinforce the existing political system rather than reforming it. ${ }^{37}$ Here, it is useful to make the distinction between political equality and human or social emancipation:

Whereas political emancipation entails granting formal political equality to individuals as citizens of their states, human emancipation is about the process through which individuals recognize and organize themselves as social beings in their everyday lives. While political emancipation is reached when all people within a state are treated as equal by the law of the land, human emancipation is realized when people treat themselves and others around them as equals. ${ }^{38}$

The argument is made that ideologies advocating 'citizenship for itself' have the effect of sustaining institutionalization processes that paradoxically increase people's subjection. Real advances, it is argued

\footnotetext{
${ }^{34}$ For more on political activism as eco-incarceration, see A. Shah, In the Shadows of the State: Indigenous Politics, Environmentalism, and Insurgency in Fharkhand, India, Duke University Press, Durham, NC, 2010.

${ }^{35}$ Gorringe and Waghmore, From the Margins to the Mainstream, p. xxviii.

${ }^{36}$ Ibid., p. xxvi.

${ }^{37}$ Ibid., p. xxvi.

${ }^{38}$ I. Roy, 'Emancipation as social equality: subaltern politics in contemporary India', Focaal, 76, 2016, p. I6.
} 
by Jaoul, are in fact promoted by emancipatory struggles whose political horizons lie beyond citizenship. ${ }^{39}$ In the final section, we consider a radical alternative that Gujjars in Chamba increasingly see as offering the possibility of genuine social emancipation. Drawing on notions of community while not being limited by them, for many Gujjars, changes in the form of Islam they practise have encouraged their rejection of state subjectivities while offering genuine possibilities for education, employment, and welfare support.

\section{Being Muslim: seeking emancipation outside of the state subjectivities}

To open the madrasa, they had to close the road. In front of the new classrooms, a group of VIPs were seated on cushions beneath a covered podium. Amongst these dignitaries, I could see Hanif Bhai. Allah Ditta was noticeably absent. In front of the podium, a large crowd spilled out into the road to listen to the distinguished speakers invited to mark the foundation of this new Islamic school: boys in white kurta pyjama and taqiya (skull caps), girls in black headscarves, and Gujjar men wearing turbans, waistcoats, and grey kameez. No women were present. It was April and the day had started brightly but, as the speeches went on, ominous thunderclouds began to build up. When the storm broke, we ran inside the classrooms. Lunch was provided - a communally cooked dham of biryani, matter paneer, and chicken. It was here that I met the Maulvi Zahid and he told me about the foundation of the school:

We Gujjars mustn't confine ourselves to buffalo herding because education is very important. You are answerable to God if you don't educate your children - girls and boys. Our country cannot progress and backwardness can't be eliminated unless Muslim children are educated. We had to start this Madrasa; we couldn't expect finance from the Government side, instead the money came from our own pocket. Two years ago the land was donated and the foundation stone laid at this place. At that time it was just a hill and within two years we have built a two storey building .... We have spent I8.5 lakh rupees but only six lakh rupees are borrowed. People have donated money and labour and remained hungry from doing this. We have made this sacrifice so that we will not be questioned by God over our children's lack of education. ${ }^{40}$

${ }^{39}$ Jaoul, 'Beyond citizenship', p. 4 .

${ }^{40}$ Zahid, interview by author, Chamba, 5 April 2015. 
Zahid was understandably busy so I returned the next day when he was free to show me the classrooms, the toilet block, the kitchen that cooks the midday meal, and the spot where a new residential hostel was planned that would allow students to stay full-time. He invited me into his office, where we drank tea and chatted about his plans for the school. Though his smart white kurta, loose pyjamas, and skullcap made him look more Delhi-style Muslim than tribal Gujjar, Zahid told me he was born in the Saal valley in a house not far from that of Hanif. Unlike Hanif, he was sent away at the age of eight to be educated at a series of madrasas in Haryana, Uttar Pradesh, and Delhi. As well as studying the Koran, he learned Arabic and Islamic jurisprudence. He could have got a job elsewhere but instead opted to return to help his community. Zahid was recruited together with his cousin, Roshan Deen, to be the 'opening batsmen' at the new school.

Jeffrey et al. suggest that, with scarce job opportunities, 'the schooling strategies of oppressed people may not follow a simple upward trajectory towards growing participation in formal education'. ${ }^{41}$ When the expected gains from formal education fail to materialize, then educational strategies 'may ... be subject instead to reassessment and reversal'. ${ }^{42}$ The opening of the new madrasa shows how, in the Gujjar case, investment in education has not necessarily been subject to reversal, but has undoubtedly been reassessed and has taken on new forms. Declining beliefs in the ideals of secular development through education have led some to promote religion over ethnicity as a focus of identity and route to social and economic advancement.

Over the last decade, a wave of religious feeling has swept through the Saal valley. ${ }^{43}$ This transformation is represented in concrete form by the string of mosques and madrasas that have been constructed where before there was none. The roots of this increase in religiosity can be traced back to the I970s. In the years that Allah Ditta was studying for his B.Ed. in Rajasthan, a small number of other Gujjars (including Zahid's father) went to Uttar Pradesh to gain an Islamic education from madrasas at

${ }^{41}$ C. Jeffrey, R. Jeffery, and P. Jeffery, 'Degrees without freedom: the impact of formal education on Dalit young men in North India', Development and Change, 35(5), 2004, pp. $963-964$.

${ }^{42}$ Ibid., p. 983 .

43 This perhaps mirrors developments in India as a whole where Banerjee reports a rise in the number of Islamic seminaries and greater emphasis placed on 'acquiring the outward symbols of Muslim identity'. M. Banerjee (ed.), Muslim Portraits: Everyday Lives in India, Indiana University Press, Bloomington, IN, 2008, p. xvi. 
Deoband and Saharanpur. These men returned and passed on what they had learned but their impact, initially at least, was not widespread. While the presence of these Deoband-educated individuals was clearly important, it was not until the subsequent generation that the boom in mosque construction took off in the Saal valley. The sons of the first Deoband-trained elders were also sent to Deobandi seminaries. They returned to Chamba a decade after Hanif Bhai made his move into politics through his GCRO. In 2006, a first madrasa was built in the area. Families who had not previously sent their children for education enthusiastically signed up to help with labour and donations so their children might learn there. The addition of a second madrasa, with Zahid as principal, means that Gujjar children need no longer be sent away for religious instruction. Together, they can accommodate $25^{\circ}$ male and 250 female pupils.

Not everyone appreciated these new madrasas. When Allah Ditta visited one of the newly opened madrasas, he was shocked by what he saw:

I visited the new Madrasa. I stayed for one hour. I keenly observed the behaviour of the students and the teachers. It is not up to standard. It is Ioo years old! Gujjars are innocent persons - they are being led by everyone.... What will they get from these madrasas? Will they be able to earn a living from the education given in a Madrasa? ${ }^{44}$

Allah Ditta is passionate in his belief that secular education is the only path to the betterment of the Gujjar community:

Although the government tries to make it easy - stipends are given, money for uniforms, midday meals there are no fees - our community has mentality of Ioo year back. Gujjaro ke mentality - logic nahi hote hai [there is no logic in the Gujjar mentality]. They are too much busy in themselves and don't look outside. ${ }^{45}$

In his own lifetime, Allah Ditta has seen dramatic improvement in education in Himachal Pradesh. ${ }^{46}$ New schools have been built, teachers trained, and programmes established that have brought the mountain state from being an educational basket case to being an exemplar of the progress that can be made through learning. All communities have made dramatic gains in levels of literacy. So why

${ }^{44}$ Allah Ditta, interview by author, Chamba, 27 April 2015.

${ }^{45}$ Ibid.

${ }^{46}$ See Table 5.3 in J. Dreze and A. Sen, An Uncertain Glory: India and Its Contradictions, Princeton University Press, Princeton, 2013. 
have so many Gujjar families decided to opt out of the government-run 'Hindi' schools and instead send their children to religious institutions? To Allah Ditta, madrasas represent no more than a negative retreat away from progress and back into faith. Such views are not unique: Jeffery et al. $^{47}$ and Ahmad $^{48}$ both relate instances of urban, English-educated Muslims accusing madrasas of failing to provide the sort of education that equips student to function in a modern, plural society or the skills and credentials required in today's labour markets. ${ }^{49}$

In 2006, a high-level parliamentary committee chaired by Chief Justice Rajinder Sachar concluded that India's Muslims were among the most excluded and alienated members in the body of the Indian citizenry. ${ }^{50}$ The Sachar Committee drew comparison between the position of Muslims and that of the SCs and STs, being subjected to pervasive and persistence patterns of marginalization in almost every aspect of their daily lives. With religious education weakly linked to state and market, ${ }^{51}$ are the already marginalized Gujjars of Chamba district further compromising their socio-economic prospects? Turning their backs on secular education, are the Gujjars rejecting ideas of modernity and progress? On both counts, I would argue not. With respect to Allah Ditta, a degree of logic is in fact clearly apparent in the ways that many Gujjars increasingly identify with Islam and choose to send their children to the local madrasa. In this section, I shall try to define that logic, first with reference to education and the possibilities of economic advancement, and then to the potential for religion as a vehicle for social emancipation.

Instead of simply seeing schools as places where skills are learned, we can also understand them as sites of discipline that embody societal norms. As such, the role of secular government schools should be to provide a sense of national identity and locate students as citizens

${ }^{47}$ P. Jeffery, R. Jeffery, and C. Jeffrey, 'Investing in the future: education in the social and cultural reproduction of Muslims in UP', in M. Hasan (ed.), Living with Secularism: The Destiny of India's Muslims, Manohar, New Delhi, 2007, p. 76.

${ }^{48}$ I. Ahmad, 'Urdu and madrasa education', Economic and Political Weekly, 37(24), I5 June 2002, pp. 2285-2287.

${ }^{49}$ Sikand details the commonplace view of madrasas as 'backwards', unconcerned with the world around them, and resistant to change (Y. Sikand, Bastions of the Believers: Madrasas and Islamic Education in India, Penguin Books, London, 2005, Chapter 4).

${ }^{50}$ Sachar Committee Report, Social, Economic and Educational Status of the Muslim Community of India, Government of India, 2006.

${ }^{51}$ A. Shaban, 'Muslim girls in Urdu medium schools of Maharashtra: progress, retention and aspirations', Economic and Political Weekly, II(25), i8 June 2016, pp. 65-70. 
within the wider society. In reality, the stigma that attaches to students from 'tribal' backgrounds leaves many feeling excluded from such places. More recently, a creeping atmosphere of 'banal Hinduism' has arguably contributed to a reluctance of Gujjar parents to commit their children (especially girls) to the government 'Hindi' schools. ${ }^{52}$ While they might have a right to education in government schools, this did not extend to being able to influence the culture or content of the syllabus. Would religious education in madrasas be any different?

I asked Zahid how the popularity of madrasa education can be explained - are they better than government schools? 'Yes-In Hindi school the students would only receive worldly education but here we also give moral education plus Urdu and Arabic - apna culture aur apni namaaz [our own culture and our own prayer]. ${ }^{53}$ A distinction is made between worldly education (duniya ki parhar) and religious education (dini talim). If secular education is supposed to equip the student to meet the challenges of a changing world (for instance, to help with finding employment in a modern economy), madrasas provide guidance on how to deal with different cultures, how to overcome moral temptations, and how to deal with the risks that accompany modern life. Religious education extends to correct standards of dress, behaviour, and association or relation with others as well as ideas of doing good and bad. In short, the madrasas and mosques of the Saal valley offer confidence, comfort, and a sense of inclusion in times of rapid change and uncertainty.

Religious identity might imbue Gujjars with a sense of collective dignity and confidence but the question remains over whether this might be successfully converted into new routes to prosperity. A teacher at the neighbouring government school described the curriculum at the madrasa as being 'purely traditional' and would, he felt, not equip students for jobs in the outside world. When I put this to Zahid, he replied that he was inspired by the example of 'progressive' Gujjars in Jammu and Kashmir who were entering the professions: 'they become engineers, doctors or agricultural scientists.' Another retired schoolteacher who now helps out in a madrasa outlined the curriculum

${ }^{52}$ For a description of how Muslims in western Uttar Pradesh feel excluded from schools due to the medium of instruction, aspects of curriculum, and the practice of teaching being dominated by upper-caste Hindus, see Jeffery et al., 'Investing in the future', pp. 63-9o. Sikand (Bastions of the Believers, pp. 97-98) also records the suspicions which many Muslim parents hold about government schools.

${ }^{53}$ Zahid, interview by author, Chamba, 5 April 2015. 
as including 'reading and writing in English, Hindi, Urdu and Arabic; religious education because this is very important, and technical education so that students might find work in factories after they graduate'. It would be, he concluded, 'a modern Madrasa' capable of offering a general education in an Islamic environment. ${ }^{54}$ Talking to parents who sent their children to the new schools, it was apparent that they believe that an Islamic education can open up avenues to economic as well as religious advancement. Some will go on to pursue further studies in madrasas in Uttar Pradesh and return, perhaps, as teachers; for others, the dream is of being one day able to journey to the 'Gulf', where the work is plentiful and the remuneration almost unimaginable. We will see later how these opportunities are largely restricted to male children. At this point, it is enough to underline that, with government jobs increasingly hard to reach, many Gujjars view madrasa education as offering alternative avenues for mobility that, though narrow, are demonstrably achievable.

Hanif's activism depends on forwarding claims of Gujjars being a unified and homogenous political entity. This is in keeping with the administrative categorization of Gujjars as an ST. Such formulations contain, it need not be said, a degree of fiction. Countering simplistic political and administrative definitions, the reality is of Chamba's Gujjars as a set of people who are increasingly economically heterogeneous and geographically mobile. Significantly, the shift to religious education paralleled the emergence of a new class of Gujjar shopkeepers, wholesalers, and contractors who have achieved success in business. Several of these individuals cut their business teeth as contractors supplying labour during the building of the hydro-power schemes in the Saal valley (which Hanif had opposed). Serving on governing bodies and contributing to the financing of madrasas, these businessmen and their families wield considerable social influence. This is most noticeable with regard to their adoption and enthusiastic promotion of the Islamic reform movement, Tablighi Jama'at.

In contrast to the government jobs and secular politics that were seen as the exclusive domain of the educated elite, many Gujjars expressed the view that it was religion that brought all Gujjars together as a community. The establishment of the madrasa showed how the diverse elements of the Gujjar community could come together in shared

\footnotetext{
${ }^{54}$ For an account of the debates over the inclusion of 'modern' elements within the curriculum of Deobandi madrasas, see Sikand, Bastions of the Believers, p. I47.
} 
endeavour: a landowner donated the site; wealthy businessmen paid for materials and hired specialist builders; farmers and buffalo herdersamong the least wealthy people in the area-volunteered their labour. Those who contributed - whether in cash or kind - explained that they were performing a religious duty_zakat or sadqa. Here, we see community organized around shared religious belief rather than a narrow ethnic identity that is increasingly fractured by the opening-up of differences in wealth and occupation. The notion of uplift that depends on 'being Muslim' as well as (or even before) 'being Gujjar' is, paradoxically, one that increasingly reflects the social activities that bring them together as a group. Significantly, this is not the kind of notion of the forest-dependent, buffalo-bound, tribal Gujjar that Hanif Bhai and his fellow social activists have built their political careers around. Here, a convincing case can be made that, far from turning inward and being 'too much busy in themselves', the increased religiosity of Chamba's Gujjars can be used as resources to increase social standing and promote upward economic mobility. ${ }^{55}$ Central to Tablighi learning is the study tour (dawah), which offers Chamba's Gujjars the chance to visit and receive fellow Tablighs throughout India. For Gujjars in Chamba, these study tours and the education opportunities provided by allied madrasas across North India offer the opportunity to build up social networks, to experience new places, open fresh perspectives, recognize new opportunities, and gain familiarity with possibilities outside of the narrow confines of the Chamba valley. And they do so not as subordinates, but explicitly as equals. Deobandi teaching disseminates a uniform religious ideology that transcends local hierarchical social structures to promote common bonds among Muslims. In interviews, Gujjars stressed that, thanks to their madrasa education and Tablighi Jama'at study tours, they were, for the first time, seen by privileged communities and classes as social equals. This observation may only extend to fellow Muslims, but it clearly holds importance to Gujjars, who have long been made to feel inferior by both Hindus and Muslims in Chamba. Cosmopolitanism is no longer the sole preserve of those, such as Allah Ditta and Hanif Bhai, whose education has been confined to schools and colleges.

\footnotetext{
${ }^{55}$ For more on the Deobandi school, see B. Metcalf, 'The madrasa at Deoband: a model for religious education in modern India', Modern Asian Studies, I2, I978, pp. IIII34. On the Tablighi Jam'at, see Y. Sikand, The Origins and Development of the Tablighi famaat (I920s-1990), Orient Longman, Delhi, 2002.
} 
The democratization of local state-society relations cannot be adequately understood as being propelled simply by an ideational or cognitive transformation. Rather, 'emotions are at the very core of mobilization' and these processes require 'a transformation on the emotional habitus of subaltern groups' ${ }^{56}$ Moving beyond the secular politics of ethnicity and caste, Mosse ${ }^{57}$ (for Christianity among South Indian Dalits) and Jaoul ${ }^{58}$ (for the adoption of Navayana Buddhism by Dalits in Uttar Pradesh) both look at transformatory potential that new forms of religion offer to historically subordinated and marginalized communities. The example of Gujjars in Chamba suggests similar possibilities through the vehicles of Deobandi Islam and association with the Muslim missionary movement, Tablighi Jama'at. In this respect, we find a moral dimension to aspiration alongside the material one. Subsuming a locally bounded ethnic dimension beneath a broader cosmopolitan Muslim identity raises status by shedding the notion of the 'backwards' Gujjar while imagining new possibilities for advancement. In doing so, Chamba's Gujjars challenge the view that progress can only be measured through proximity to the state and a narrow ideal of secular education. Where once the secular state was seen as the vehicle of modernity, it is now the institutions of Islam that offer the best chance of escaping from poverty and the low social status that attach to tribal identity.

For adherents of Tablighi Jama'at, in line with the teaching of the original Deoband movement, religion becomes 'a matter of personal, private life, separate from politics'. This 'interiorization and individualization of religious practice' can be constructed as being 'truly secular'. ${ }^{59}$ In this respect, a movement often see as 'traditional' is, in fact, strikingly different: 'new in its reach, new in its lay organization, new in its intensity, new in its modes of communication and organization, new in its self-consciousness as it deliberately strikes a

${ }^{56}$ A. G. Nilsen, "'Real, practical emancipation?": subaltern politics and insurgent citizenship in contemporary India', Focaal, 76, 2016, p. 37.

${ }^{57}$ D. Mosse, The Saint in the Banyan Tree: Christianity and Caste Society in India, University of California Press, Berkeley, CA, 2012.

${ }^{58}$ N. Jaoul, 'Citizenship in religious clothing? Navayana Buddhism and Dalit emancipation in late i99os Uttar Pradesh', Focaal, 76, 2016, pp. 46-68.

${ }^{59}$ B. Metcalf, "Traditionalist" Islamic activism: Deoband, Tablighis, and Talibs', in B. Metcalf (ed.), Islamic Contestations: Essays on Muslims in India and Pakistan, Oxford University Press, New Delhi and NEw York, 2004, p. 275 
"counterculture" relationship to economic and political life. ${ }^{, 60}$ In line with these principles, many Gujjars express a feeling of distaste for engaging with the state in order to access welfare benefits. Rejecting institutionalization as a backwards tribal community, ${ }^{61}$ they stress that Gujjars 'should not take from the Government', but instead 'we should stand on our own feet'. However, these feelings do not indicate a sense of outright disaffection towards the state nor a rejection of a sense of citizenship. $^{62}$ Rather, they are informed by degrees of pragmatism, acceptance, and resilience. Though inflected by a healthy degree of cynicism, voter participation among Gujjars remains strong-including among those closely associated with Tablighi Jama'at. ${ }^{63}$ Returning to the case of the madrasa at Badagaon, it is notable that grants were obtained from the Panchayat Samiti to support its construction. Furthermore, both the Himachal Pradesh state and the national government contribute to the madrasa by covering the cost of some of the teachers' salaries (under the Scheme for Providing Quality Education in Madrasas (SPQEM)). What is notable here is the emergence of a new orientation to politics that is national rather than purely local in its emphasis. Making clear the rightful claim of India's Muslims to a full sense of nationality and citizenship, the speeches made at the opening of the madrasa emphasized the contribution of Deobandi scholars to the freedom struggle.

Perhaps it would be best to view what is happening among Gujjars in Chamba not as a withdrawal from the state, but as a reorientation to it: welfare rights and other state entitlements are given up, as is the promotion of Gujjars as a separate tribal constituency. Rejecting group-differentiated concepts of citizenship, fresh claims are made to a sense of identity and belonging in terms of equality within a larger national-civic entity. By engaging in an emancipatory struggle whose political horizons lie beyond citizenship, Muslim Gujjars feel empowered to negotiate with the state not as tribal supplicants, but as full citizens.

${ }^{60}$ B. Metcalf, 'Nationalism, modernity, and Muslim identity in India before I947', in Metcalf, Islamic Contestations, p. 178.

${ }^{61}$ Roy, 'Emancipation as social equality', p. 27.

62 They share this pragmatic orientation with the Muslim weavers of Varanasi described by P. Williams, 'An absent presence: experiences of the "welfare state" in an Indian Muslim mohallā', Contemporary South Asia, I9(3), 201 I, pp. 263-280.

${ }^{63}$ One even went so far as to say that a vote for the Bharatiya Janata Party was 'a vote for development', though, he added, the benefits would not extend to Muslims. 


\section{The uneven distribution of emancipatory alternatives}

As described in the previous section, many Gujjars have, over the last decade, actively sought to foreground a Muslim identity that they believe can provide an alternative route to economic and social advancement. The new registers of personal and collective identity promoted through association with Islamic reform movements such as Tablighi Jama'at suggest a decisive shift in - though not necessarily a move away from-notions of Indian citizenship among Gujjars in Chamba. The reasons for these shifts are complex - in part, they may be due to the sense that there is little benefit in conforming to official acts of reductive categorization, in part because other alternatives are now available that offer opportunities for economic and social advancement, and, in part, because of the rise of Hindu nationalist discourses that reduce identity to a simple binary of belonging. While Hanif operates within dominant hierarchies of power (and the possibilities of his activism are limited by them), the case of the madrasa shows how the adoption of religious identities has liberated Muslim Gujjars in Chamba district to pursue their own interests, define their own culture, and support their own forms of prayer.

Relating the Gujjar turn towards religion to possibilities for emancipation from state subjectivities throws up a number of questions about the forms and limits of insurgent citizenship. With many Gujjars feeling liberated to pursue their own interests, we must ask how these interests are defined and by whom. As Holston points out, the agendas pursued by new forms of social movement are by no means necessarily just, good, or egalitarian. ${ }^{64}$ Not all Gujjars have been able to gain moral and material advantage from the new emphasis placed on their identity as Muslims and association with religious education networks. With Gujjars' 'tribal' identity giving way to the 'Muslim' one, the distribution of the perceived advantages of emancipation outside of the state subjectivities need to be examined.

In part, the attraction of Deobandi teaching is that it emphasizes equality and offers connection with Islamic networks across India. It is notable that the religious enthusiasm is most evident among the better-off among Chamba's Gujjar community and particularly the emerging class of entrepreneurs who have benefitted most from the liberalization of the economy. For them, the opportunities potentially

${ }^{64}$ Holston, 'Insurgent citizenship', p. 248. 
available through integration into India-wide business networks are tied up with a sense of social emancipation derived from moving beyond the administrative and political subjectivities of tribal identity. Poorer Gujjars are less well positioned to enjoy the material or emotional benefits that arise from emphasizing religious rather than ethnic affiliation. Their dependence on state welfare schemes means they also have more to lose. We saw in the example of Allah Ditta that reservation programmes intended to bring about equality can result in heightened inequality within the social group. Though only a small number of families have benefitted from economic mobility through business, they are able to exert a disproportionate influence. Newly minted businessmen boast of the 'social work' they do for the benefit of the wider community. This might take the form of giving loans to poor families in times of need, finding jobs for kinsmen without work, or funding the construction of mosques and madrasas. In these efforts, the new Gujjar elite unselfconsciously echo the paternalistic discourses employed by the Nehruvian state as they remake the Gujjar community. The interests of the poorest - protection of grazing access and a guaranteed right to work as supported by Hanif Bhai and Sheena Begum - risk being subsumed beneath the new interests and connects of the emergent middle class.

If the emancipatory possibilities of insurgent citizenship are shaped by wealth, it is also clear that, in the Gujjar case, the possibilities for individual and collective aspiration are heavily gendered. Thus far, Gujjar women have featured only intermittently in this account - the three individuals selected as exemplars of particular trajectories have all been male. The first point to make is that - as mediated between the Gujjar community, the wider society, and the state - the forms of identity that have always been prioritized have been those that predominantly privilege men alone. This is not to say, however, that women have not been impacted by these trends. In the remainder of this section, we examine the gendered basis of insurgent citizenship and the ways these shape aspirations among women and men.

Very few women of Allah Ditta's generation took advantage of the places in government schools that were available to them, and there were none who benefitted from affirmative action in terms of the reservation of government jobs. And yet, as Hanif's wife, Sheena Begum, boasts, Gujjar women have never worn the veil and have traditionally enjoyed a comparatively high status and degree of social freedom. When the leadership of Badagaon's panchayat was reserved for a female candidate, Sheena won election to the position of Pradhan. 
Sadly, her enthusiastic engagement in social and political activism has brought only limited returns, mostly in the form of collective mobilization to promote healthcare for women, birth control, and campaigns against child marriage. The low enrolment rate for female Gujjars in government schools is in stark contrast to the popularity of Islamic education. ${ }^{65}$ At the madrasa, parents and teachers emphasized the importance of education for girls and pointed out that those who previously would not have attended school were now learning to read and write. In a couple of cases, female students - both from relatively well-off families - had gone on to study at higher level institutions in Surat and Jammu. However, talking to their families, it became apparent that resulting opportunities were likely to be constrained by the new religious norms of seclusion that formerly many would have considered alien to Gujjar cultural traditions. Evidence from studies of madrasa education-particularly the emphasis placed on producing Muslim women who are 'demure, self-controlled [and] respectable ${ }^{66}$ suggests that, though girls might have a right to education, they have less in the way of rights in or through education. This places Gujjar women on the wrong side of three interlocking forms of disadvantageas part of a minority tribal group, as Muslims within a majority Hindu population, and as women within a Muslim community group in which the claims to status among men are increasingly related to limits placed on the activities of female family members.

Discussion of the emancipatory alternatives of insurgent citizenship have allowed us to move beyond a dominant, statist conception of citizenship. However, the Gujjar example illustrates that, if such changes may loosen the bonds of state subjectivities and low social status for some, they may also condemn others to new forms of marginalization through the remaking of gender relations and growing economic inequality within the social group. For wealthy Gujjar men, the benefits of accepting a more cosmopolitan religious identity are obvious; but the moral, material, and social advantages are less accessible to Gujjar women and the poorest of the community. A close examination of the claims of insurgent citizenship draws attention to the

${ }^{65}$ R. Axelby, in A. Shah et al., Ground Down by Growth.

${ }^{66}$ P. Jeffery, R. Jeffery, and C. Jeffrey, 'Islamization, gentrification and domestication: a girls' Islamic course and rural Muslims in western Uttar Pradesh', Modern Asian Studies, 38(I), 2004, pp. I-53. 
tensions that arise out of conflicting aspirations and prompts us to consider whose emotions are being mobilized, and to what effect.

\section{Competing visions and vehicles for insurgent citizenship}

If India's nationhood is constructed out of the articulation of different discourses of citizenship, then the holding-together of the nation state depends on the degree of legitimacy that its diverse citizens confer upon it. ${ }^{67}$ The possibilities of insurgent citizenship - of how ordinary people frame and make demands on the state, how they contest its foreclosures, and attempt to exceed its bounds - are therefore important in that they make the basis for claims for inclusion within the nation and articulate new understandings of the relationship between state and citizen.

This article has shown the complex and sometimes contradictory ways by which individuals and social groups have sought to negotiate the shifting plate tectonics of citizenship in Himachal Pradesh. In it, we have followed the lives and careers of three Gujjars in Chamba district who, in different ways, might be seen as leaders of their community. Allah Ditta, Hanif, and Zahid might be described as outliers, exceptions, and pioneers, but each embodies different visions of identity and possible vehicles of progress. Respectively, they owe their positions to official programmes of affirmative action, political activism based on ethnic identity, and through incorporation into the education institutions and social networks of Deobandi Islam. In pursuit of their ambitions - a secular education and good government job, an equitable distribution of state resources and welfare provisions, a sense of social emancipation derived from moral status - each has adopted different strategies. For each, there are tensions between the aspirations of the individual and those of the collective; each requires a calculation of the tensions between state subjectivities and emancipatory possibilities. These relationships between state and citizen are structured along particular lines - the possibilities they offer are shaped by ethnicity, religion, class, and gender. In each case, very real gains can be identified as new opportunities for social and economic advancement have opened up; in each case, these gains are unevenly distributed. Each of these strategies has allowed Gujjars to access certain facets of citizenship - variously, incorporation into a national mainstream,

${ }^{67}$ Shani, 'Conceptions of citizenship in India', p. 148. 
political and civic rights, claims to social welfare, extended political ties, and feelings of shared belonging - though noticeably each form of claim comes without a corresponding denial of other aspects of citizenship.

Against these emancipatory potentials, the stories of Allah Ditta, Hanif Bhai, and Zahid, tracked over four decades, also chart a clear closing-down of both the range of identities through which the state classifies claimants and the associated discourses used to make claims on the state. We see this in the decline of the ideal of the secular Nehruvian state that established itself with the aim of bringing unity to India's social and cultural diversity. We see it in the rise of identity politics that leaves those lacking political influence as losers in the fight over government resources. It is found in the increasing inequality that has resulted from the post-I9gos liberalization of the Indian economy. It is also apparent in the religious polarization brought about by the rise of Hindu nationalism. In I970, Parry described the Koli facing a choice between two possible forms of caste identity. Options still exist but, four decades on, the Gujjar dilemma is how to avoid being boxed into increasingly narrow and prescriptive forms of identity. Behind administrative categories like 'ST', ethnic categories like Gujjar, or religious categories like Muslim, there exist heterogeneous realities that are inflicted with intra- and inter-community power relations and conflicts. People's movements that forward claims to political and social emancipation work best when they open up possibilities for hybrid and creative political cultures. The potential of Gujjars to advance individually and collectively depends on their ability to maintain equitable relationships within their own community while constructing mutually supportive alliances with other groups of insurgent citizens. 